\title{
A Switched Reluctance Motor Drive using Photovoltaic Transistors: Principle, Prototype, Experimental and Numerical Results
}

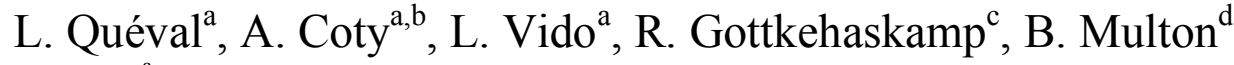 \\ ${ }^{a}$ SATIE CNRS, University of Cergy-Pontoise, Cergy-Pontoise, France \\ ${ }^{\mathrm{b}}$ Saurea, Auxerre, France \\ ${ }^{\mathrm{c}}$ Lab for Electrical Machines, University of Applied Sciences, Düsseldorf, Germany \\ ${ }^{\mathrm{d}}$ SATIE CNRS, ENS Rennes, Bruz, France
}

\begin{abstract}
A solar-powered switch reluctance motor drive using photovoltaic transistors is presented. The expression "photovoltaic transistor (PVT)" is used to designate a conventional photovoltaic cell used as a light-controlled power transistor. To obtain a motor drive, a set of PVTs controls the current fed from an external DC power source to the motor phases. The control is achieved by modulating the sunlight hitting the PVTs using a shutter driven by the motor rotor. If the external DC source is a solar panel, the resulting system is able to convert light energy into mechanical energy, without the need of any brushes or other power electronics components. This system could be more affordable and reliable than conventional ones, and therefore is well suited for off-grid applications like water pumping. This article first discusses the operation of a photovoltaic transistor through the proposition and the validation of a model. Then, the operating principle of a PVT inverter is clarified. Finally, experimental and numerical results on the first PVT inverter-fed switched reluctance motor are reported. A prototype was built using a switched reluctance motor 6/4 and 12 PVTs. It was here connected to an external $12 \mathrm{~V}$ DC power source as a step before using a solar photovoltaic source. Results showed that the PVT inverter-fed switched reluctance motor was operating as expected and provided useful power.
\end{abstract}

Keywords-photovoltaics, solar cell, inverter, switched reluctance motor, water pumping.

\section{INTRODUCTION}

In today's market, there exist already electric motors driven by light through photovoltaic cells. But, such motors require brushes [1] or DC/AC converters [2]. This limits the reliability of these motors and subjects them to maintenance, making this technology unsuitable for some applications, like water pumping in isolated areas. In this context, earlier we built a "photovoltaic motor" (Fig. 1c) [3, 4]. This is an electric motor using photovoltaic (PV) cells optically controlled by a shutter driven by the motor rotor to convert light energy into mechanical energy, without the need of any brushes or other power electronics. The photovoltaic motor potentially requires little maintenance and could have a low cost on overall life cycle. But its controllability is limited, and so its efficiency is low.

We investigate here a new architecture that is shown in Fig. 1d: the photovoltaic transistor inverter-fed switched reluctance motor (SRM) [5]. As photovoltaic motors, it uses PV cells optically controlled by a shutter connected to the a)

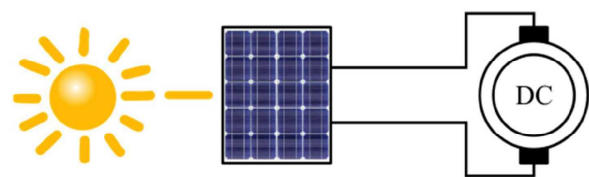

b)

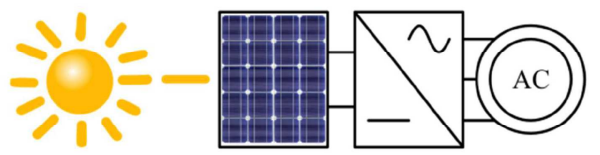

c)

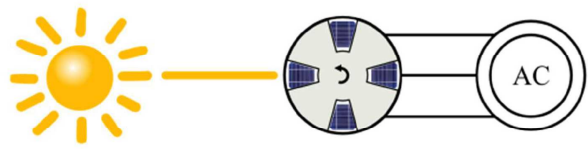

d)

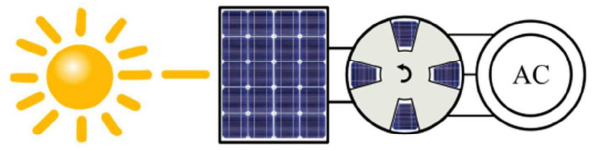

Figure 1. (a) PV cells + DC motor, (b) PV cells + power electronics $+\mathrm{AC}$ (brushless) motor, (c) Photovoltaic motor [3,4], (d) Photovoltaic transistor inverter-fed motor.

rotor. However, here the PV cells are not used as current generators, but as light-controlled power transistors (PVT) that control the current fed to the motor from an external DC source (also photovoltaic). Such architecture has the same advantages and limitations as the photovoltaic motor. But for a given shutter diameter (imposing a mechanical constraint), the power output of a PVT inverter-fed SRM is higher than a photovoltaic motor. Note that there is no energy storage system: the motor is stopped when there is no sunshine (as any other solar system without energy storage). The intended application should therefore comply with such operation, like water pumping with storage in a water tank [6-8].

On the one hand, various patents exist about the optical control of the current fed from an external source to a motor by means of photosensitive elements and a shutter driven by the rotor. $[9,10,11]$ proposed to drive a permanent magnet synchronous motor (PMSM) with unipolar currents switched by photodiodes, phototransistors or photoresistors. [12, 13] presented various configurations where the PMSM currents were bipolar. [14] patented a light-activated thyristors converter-fed PMSM. [15] used solar cells to drive a PMSM 


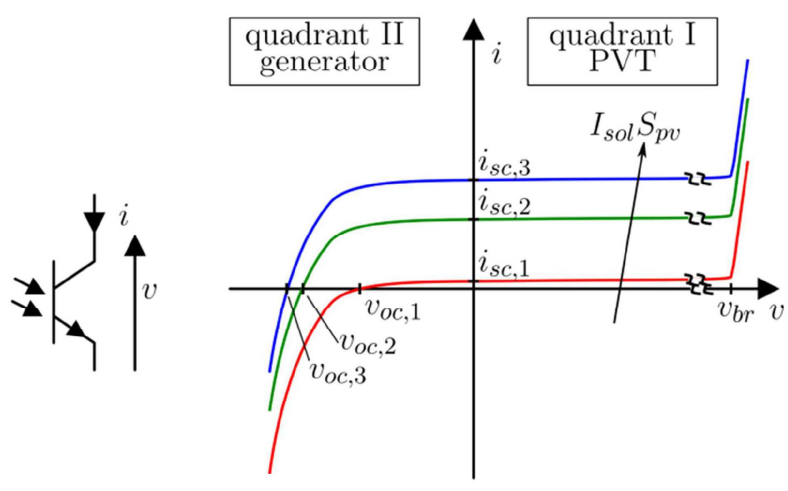

Figure 2. Photovoltaic transistor convention and idealized current-voltage curves for various $I_{s o l} S_{p v} . v_{o c}$ is the open-circuit voltage $(\sim 0.6 \mathrm{~V}) . v_{b r}$ is the breakdown voltage $(10-30 \mathrm{~V}) . i_{s c}$ is the short-circuit current.

\section{PVT (stationary)}

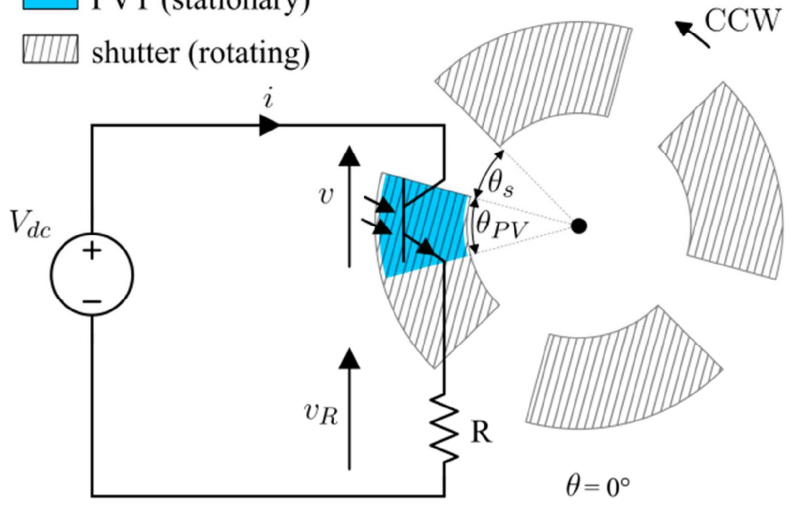

Figure 3. Photovoltaic transistor characterization experimental setup $\left(\theta_{P V}=\theta_{s}=30 \mathrm{deg}\right)$.
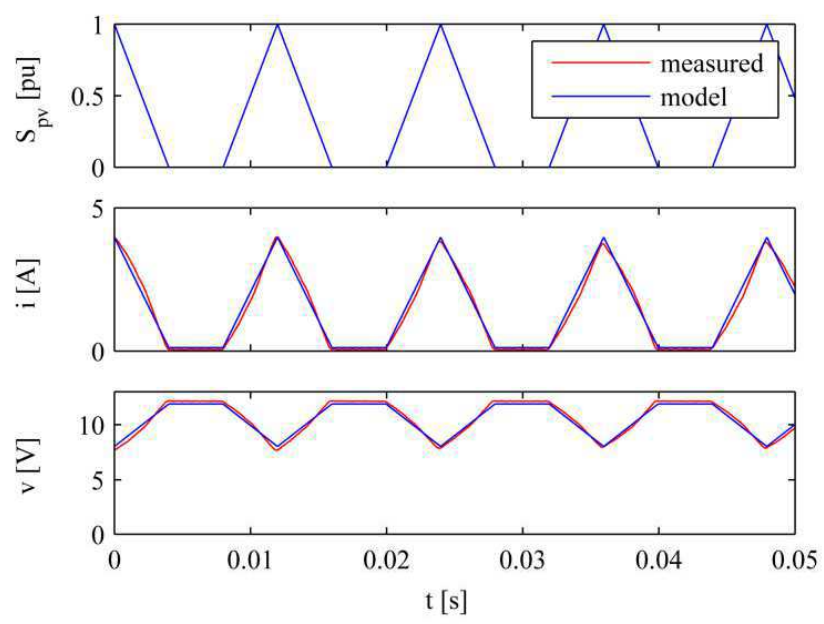

Figure 4. Photovoltaic transistor characterization experimental and simulation results $\left(R=1 \Omega, V_{d c}=12 \mathrm{~V}, I_{s o l} \approx 600 \mathrm{~W} / \mathrm{m}^{2}, 1252 \mathrm{r} / \mathrm{min}, \sim 43^{\circ} \mathrm{C}\right)$.

with bipolar currents. [16] patented a switched reluctance motor controlled with solar cells. On the other hand, the

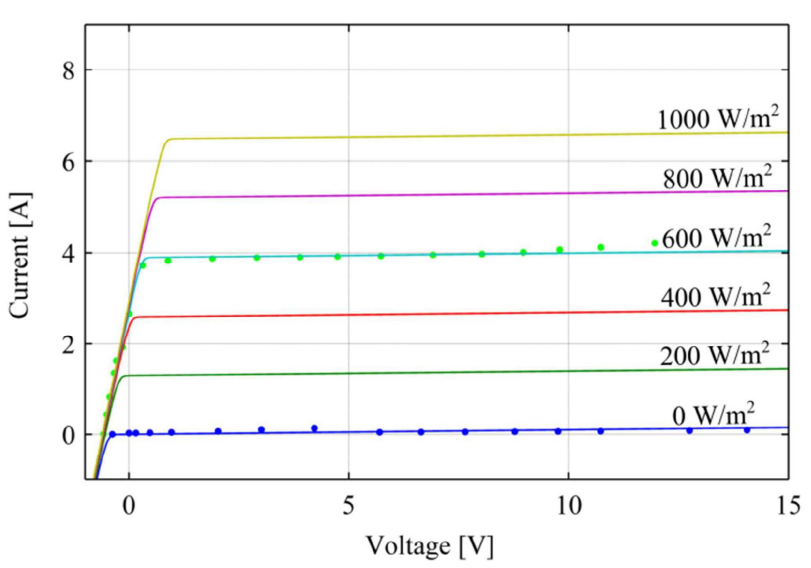

Figure 5. Photovoltaic transistor current-voltage curves for various $I_{\text {sol }}$, measured at $\sim 43^{\circ} \mathrm{C}$ (dots) and simulated (lines), below breakdown voltage.

scientific literature on the topic is very scarce. The only work we could find on the topic is [17]. In that work, the author studied, experimentally only, a photovoltaic transistor inverter-fed PMSM with unipolar currents. He notably showed that the no-load rotation speed depends on the relative angle of the rotor and of the shutter. But no useful power could be obtained with the prototype, and no model was proposed to help us understand and optimize the system.

We tackle here these two points in a bottom-up approach. First, we study the operation of photovoltaic cells used as photovoltaic transistors. A model is developed and validated. Then, we explain in details the working principle of a photovoltaic transistor inverter-fed switched reluctance motor. Finally, we verify the concept by building a prototype and comparing experimental data with simulations.

\section{Photovoltaic TRANSISTOR}

\section{A. PVT operation}

In this article, we adopt the convention shown in Fig.2 with the understanding that the symbol represents a photovoltaic transistor (and not a phototransistor). The classical operation quadrant of a photovoltaic (PV) cell is quadrant II (generator). If we operate the PV cell in quadrant I, it can be used as a light-controlled transistor (PVT). Indeed from Fig. 2, for a given polarization $0<v<v_{b r}$, the current $i$ is approximately equal to the short circuit current $i_{s c}$. And $i_{s c}$ is approximately proportional to the product of the normal solar irradiance $I_{s o l}$ by the normalized illuminated surface $S_{p v}$. Therefore, one can control the PVT current by varying $I_{s o l}$ or $S_{p v}$.

To clarify the PVT operation when $S_{p v}$ varies and $I_{s o l}$ is constant, consider the experimental setup shown in Fig. 3: a PVT and a resistance are connected in series with a DC voltage source. The illumination on the PVT is modified by a shutter rotating in the counterclockwise direction (CCW). The PVT is a PV cell MPO Solo (monocrystalline silicon), efficiency $18.8 \%, i_{s c}=8.897 \mathrm{~A}$, and $v_{o c}=0.640 \mathrm{~V}$ at standard testing conditions [18]. It is cut merely so that the PVT angle 

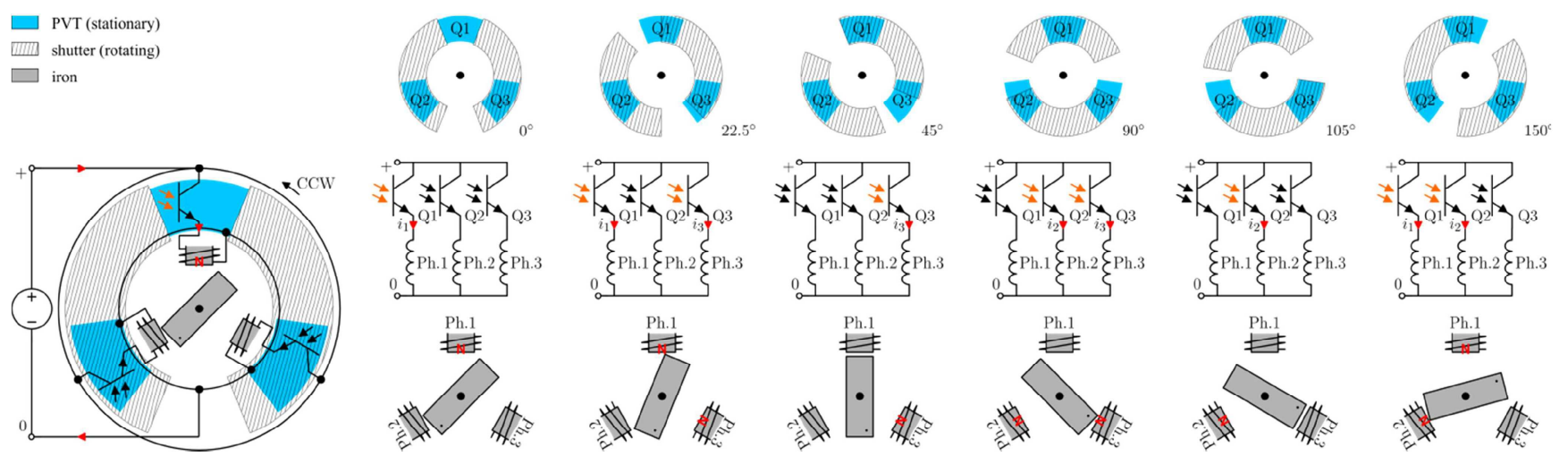

Figure 6. Three-phase PVT inverter-fed SRM, overview and operating principle (simplified magnetic circuit).

$\theta_{P V}$ and the shutter aperture angle $\theta_{s}$ are both 30 degrees. The measured PVT voltage and current are shown in Fig. 3. When the shutter blocks the light on the PVT $\left(S_{p v}=0 \mathrm{pu}\right)$, the PVT current is almost zero ie. the PVT is OFF. As a result, the PVT voltage is $V_{d c}$. But when the shutter lets the light hit the PVT $\left(S_{p v}>0 \mathrm{pu}\right)$, the PVT current is positive ie. the PVT is ON. Besides, the PVT current is to a good approximation proportional to the illuminated surface $S_{p v}$. The PVT voltage is then approximately equal to $V_{d c}-R i_{s c}$. We carried out measurements for shutter rotation speeds ranging from $100 \mathrm{r} / \mathrm{min}$ up to $1250 \mathrm{r} / \mathrm{min}$, and $V_{d c}$ between 8 and $12 \mathrm{~V}$. In that range, a similar behavior was observed and no capacitive effect was noticeable. This is the ground for using a static model in the following.

\section{B. $\{P V T+$ shutter $\}$ modeling}

We call photovoltaic transistor a conventional photovoltaic cell used as a light-controlled power transistor. It can therefore be simulated using the well-known 1-diode model (below breakdown voltage) [19]. From above observations, the shutter optical control is modeled by multiplying the input irradiance $I_{s o l}$ by the normalized illuminated surface $S_{p v}$. With the convention of Fig. 2, the PVT current $i$ and voltage $v$ are linked by

$$
i=I_{s o l} S_{p v} \frac{I_{p h 0}}{I_{s o l 0}}-I_{s}\left(\frac{e^{\left(-v+R_{s} i\right)}}{N V_{t}}-1\right)-\frac{-v+R_{s} i}{R_{p}}
$$

where $I_{p h 0}$ is the measured solar-generated current for a given irradiance $I_{\text {solo }}, I_{s}$ is the diode saturation current, $R_{s}$ is the series resistor, $N$ is diode quality factor, $V_{t}$ is the thermal voltage, and $R_{p}$ is the parallel resistor. The variation of the PVT parameters caused by the temperature is here neglected [19]. This model is equivalent to the model using lookup tables used in [4], but proves to be numerically faster and more stable. The implementation is done with Matlab Simulink and the Simscape toolbox [20].

\section{PVT model calibration}

To reduce the uncertainties, the parameters of the PVT model must be obtained from measurement of the same PVT, under the same light source and for the same average temperature [4]. Therefore, the PVT current-voltage curves shown in Fig. 5 were recorded right after the measurements reported in Fig. 4. The parameters of the 1-diode model are then obtained by trial and error, so that the model fits the measured current-voltage curves. In this process, it is useful to point out that $R_{s}$ affects the slop of the curve at the opencircuit voltage, while $R_{p}$ determines the slop of the curves in quadrant I. Note that the test bench irradiance was estimated to $\sim 600 \mathrm{~W} / \mathrm{m}^{2}$ by using a PV cell calibrated under sunlight.

\section{PVT model validation}

We performed the simulation corresponding to the setup shown in Fig. 3. Results are well in line with the measurements as shown in Fig. 4. Similarly, close alignments were obtained for shutter rotation speeds ranging from $100 \mathrm{r} / \mathrm{min}$ up to $1250 \mathrm{r} / \mathrm{min}$, and $V_{d c}$ between 8 and $12 \mathrm{~V}$. This validates the proposed PVT model.

\section{PVT INVERTER-FED SRM}

\section{A. Circuit and operation}

For simplicity's sake, we consider here a simplified 3phase SRM [21] having 3 stator teeth and 2 rotor teeth (SRM $3 / 2$ without back yoke). The aim is not to introduce an optimal system, but to demonstrate the operating principle. The adopted inverter topology has one switch per phase, where each switch is a PVT (Fig. 6). The optical control of the PVT is obtained by using a shutter that is mechanically connected to the rotor, and that rotates synchronously with it. The DC voltage source could be replaced by a solar PV source for autonomous operation.

A step-by-step operation of the PVT inverter-fed SRM is shown in Fig. 6. For an SRM 3/2, the PVT angle $\theta_{P V}$ and the shutter aperture angle $\theta_{s}$ are selected to be 45 degrees so that there is no generator (breaking) torque during operation. Assuming the rotor initial angle is between -15 and 15 degrees, the shutter lets the light hit PVT Q1. PVT Q1 is conducting, a current $i_{1}$ magnetizes the armature coil Ph.1. This causes the rotor to rotate in the $\mathrm{CCW}$ direction to reduce reluctance. This rotation lets progressively the light hit PVT Q3. As a result, a current $i_{3}$ magnetizes the armature coil Ph.3. After a 45 degrees rotation, the shutter blocks the light on PVT Q1. The current $i_{1}$ goes to zero, as well as the armature coil Ph.1 magnetization. But PVT Q3 is still conducting: the 
magnetization of the armature coil Ph.3 causes the rotor to go on rotating in the CCW direction. Similarly PVT Q2 becomes conducting, and allows the magnetization of $\mathrm{Ph} .2$ by the current $i_{2}$. After a 105 degrees rotation, the shutter blocks the light on PVT Q3. The current $i_{3}$ goes to zero, as well as the armature coil Ph.3 magnetization. PVT Q2 maintains the rotation till the light hit again PVT Q1. Thus, a positive torque is generated continuously. The inherent torque ripple is acceptable for the type of application envisaged.

Note that with this simple architecture, only one sense of rotation is possible and the rotor speed depends on the irradiance. Besides, there is no current freewheeling: the demagnetization is dissipative (see details in section III.E(B).

\section{B. PV cell utilization factor}

The main drawback of "photovoltaic motors" is that only a small percentage of the total photovoltaic cell area is exposed to light at any given time. This is because the shutter blocks the light on all the cells, periodically. As a result, the maximum PV cell utilization factor is $1 / 3$ [3]. In the PVT inverter-fed SRM, the shutter blocks the light only above the PVTs, whereas the cells of the external solar PV source are always exposed to the light. This allows us to obtain an overall PV cell utilization factor close to 1 . A direct consequence is that, for a given shutter diameter, the power output of a PVT inverter-fed SRM is higher than a photovoltaic motor.

\section{Prototype and measurements}

To verify the concept, we built the prototype shown in Fig. 7 on its test bench with halogen lamps and a brake. The motor is a SRM 6/4 made of UI transformer cores [4]. Two stator coils are winded around each stator core, forming one half-phase (Fig. 8). Because there is no mutual coupling between the half-phases, one can define an equivalent halfphase coil $\mathrm{B}_{0}$ (Fig. 9). The parameters of the SRM are given in Table I. The resistance of $\mathrm{B}_{0}$ is $0.21 \Omega$, and its flux linkagecurrent characteristic is shown in Fig. 10. Each coil is then connected in series with one PVT, similar to the one described in section II. The PVT assembly is shown in Fig. 11. Transil diodes (voltage surge protector, $v_{b r, t}=27 \mathrm{~V}$ ) are connected in parallel to the PVTs in order to protect the PVTs from breakdown voltage (Fig. 9). The PVT optical commutation control is parameterized by the synchronization angle $\theta_{0}$ defined in Fig. 12.

In this article, as a first step and to facilitate testing, the external solar PV source is replaced by a $12 \mathrm{~V} \mathrm{DC}$ power source. For the following measurements, one half-phase is disconnected ie. only 5 half-phases are connected. Fig. 13 shows the measured half-phase current $i_{0}$, voltage $v_{0}$, and PVT voltage $v$ for various applied braking torque $T_{M}$, under a mean illumination of $\sim 600 \mathrm{~W} / \mathrm{m}^{2}$. The measured torque-speed curve and output power-speed curve of our prototype are plotted in Figs. 14 and 15. The current and voltages were measured with a ZES Zimmer LMG500. The brake is a Magtrol AHB 1.5. This shows that the PVT inverter-fed switched reluctance motor is operating as expected, and provides a useful output mechanical power. Finally, we underline that the motor is able

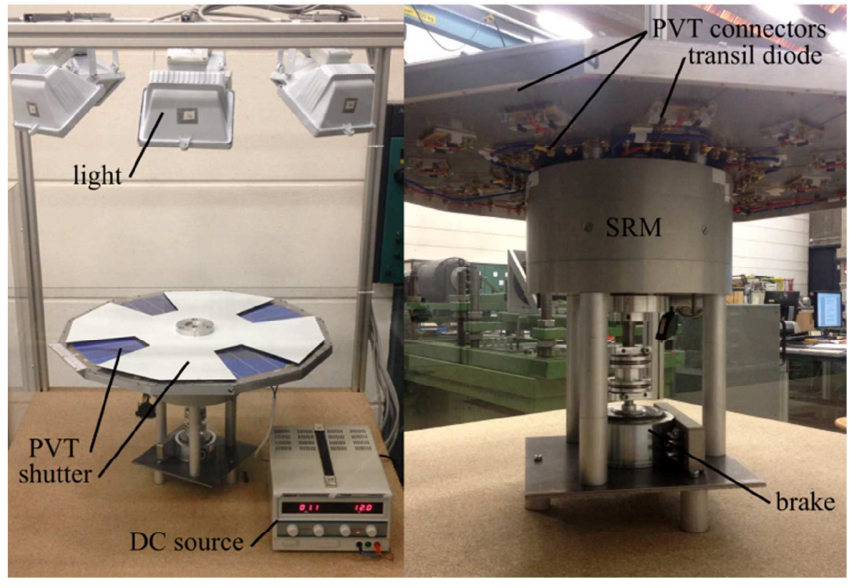

Figure 7. PVT inverter-fed SRM prototype and its test bench.

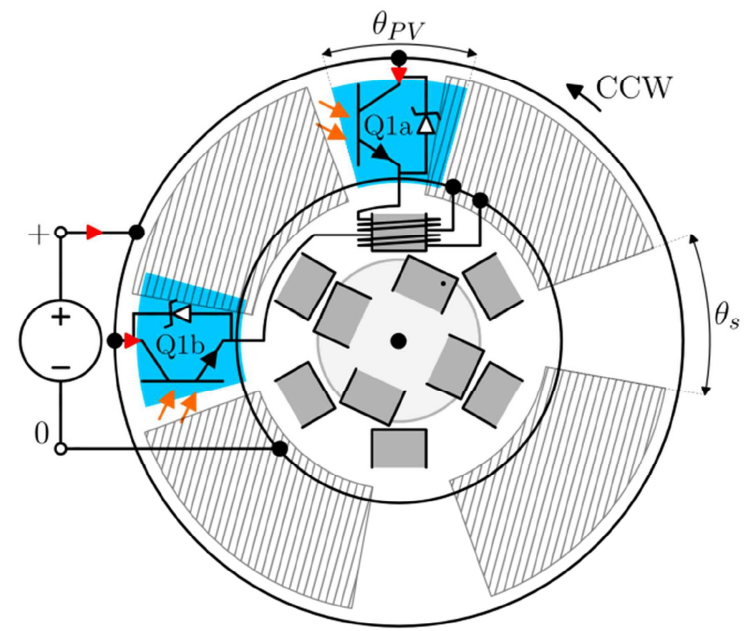

Figure 8. PVT inverter-fed SRM prototype overview (only one half-phase is shown, simplified magnetic circuit).

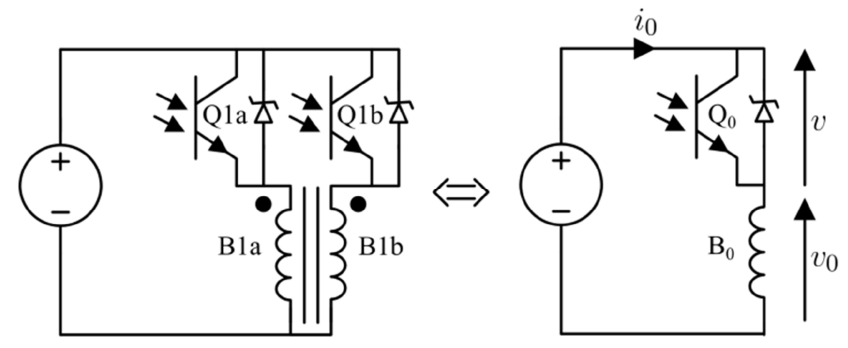

Figure 9. PVT inverter-fed SRM prototype electrical circuit of one halfphase and its equivalent circuit.

to self-start from any initial position. The operation with one half-phase disconnected is a further proof of the reliability of the system.

\section{Modeling and validation}

In order to understand the complex interaction between the PVTs and the SRM, we develop in the following a numerical model of the system. Beyond this article, the model aims at 
Table I - SRM dimensions and ratings

\begin{tabular}{|c|c|}
\hline Parameter & Value \\
\hline \hline Stator/rotor poles & $6 / 4$ \\
\hline Rotor outer diameter & $100 \mathrm{~mm}$ \\
\hline Stator outer diameter & $232 \mathrm{~mm}$ \\
\hline Airgap & $0.1 \mathrm{~mm}$ \\
\hline Effective length & $75 \mathrm{~mm}$ \\
\hline Half-phase resistance & $0.21 \Omega$ \\
\hline Half-phase aligned inductance & $24.2 \mathrm{mH}^{(\mathrm{a})}$ \\
\hline Half-phase unaligned inductance & $1.4 \mathrm{mH}^{(\mathrm{a})}$ \\
\hline Rated half-phase current & $18 \mathrm{~A}^{(\mathrm{b})}$ \\
\hline Rated power & $150 \mathrm{~W}^{(\mathrm{b})}$ \\
\hline Rated speed & $700 \mathrm{r} / \mathrm{min}^{(\mathrm{b})}$ \\
\hline
\end{tabular}

(a) cf. Fig. 10.

(b) for $I_{\text {sol }}=1000 \mathrm{~W} / \mathrm{m}^{2}$ and $\mathrm{V}_{\mathrm{dc}}=12 \mathrm{~V}$.

helping us to evaluate the range of application of PVT inverter-fed SRMs, then to optimize the output power with minimal global cost. The modeling difficulty lies in correctly taking into consideration the SRM nonlinearity, the high level of integration, and the uncommon dynamic operation of the PV cells.

We assume that the DC power source is a perfect voltage source. Because each half-phase is magnetically independent, it is enough to simulate one half-phase using the equivalent circuit shown in Fig. 9. The total torque is then estimated by multiplying the average torque by the number of half-phases. We model the equivalent $\mathrm{PVT} \mathrm{Q}_{0}$ with the $\{\mathrm{PVT}+$ shutter model introduced in section II, with multiplying coefficient to account for the two PVTs in parallel [19, eq. (24)]. We model the equivalent phase $\mathrm{B}_{0}$ with a nonlinear abc-model using one 2D lookup table for the current-flux linkage and one 2D lookup table for the electromagnetic torque [22, 23].

We performed the simulation corresponding to our prototype. Results have been added to Figs. 13, 14 and 15. Initially, the parameters of the PVT 1-diode model were obtained by trial and error similarly to what was done in section II.C. But, the estimated OFF-state PVT current was too high; therefore we increased $R_{p}$ until simulation and measurements matched. Despites the uncertainties linked to the various parts of the system, our model predicts accurately the half-phase current and voltage. This validates our modeling approach. Nevertheless, the output power is overestimated by up to $10 \%$. This discrepancy can be explained by various factors. (i) We assume that all the halfphases are identical. In particular, we assume no dispersion of the PVTs parameters. (ii) We assume an average PVT operating temperature when calibrating the PVT model parameters (section II.C). But the PVT temperature varies with the phase current, and with the shutter rotation that increases convection cooling. (iii) We use the friction torque measured at room temperature, but the viscosity coefficient of air increases with the temperature. (iv) We use a simplified iron loss model. (v) The irradiance on the test bench is not perfectly uniform and might depend on the halogen lamp temperature.

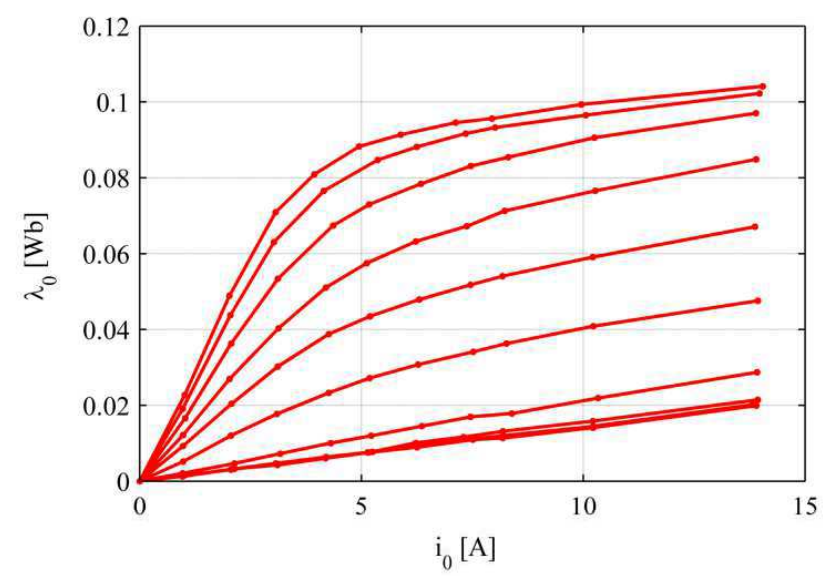

Figure 10. Flux linkage-current characteristic $\lambda_{0}\left(\theta, i_{0}\right)$ of the equivalent coil $\mathrm{B}_{0}$ (defined in Fig. 9) obtained from measurements. $\theta=0,5,10,15,20,25$, $30,35,40,45 \mathrm{deg}$.

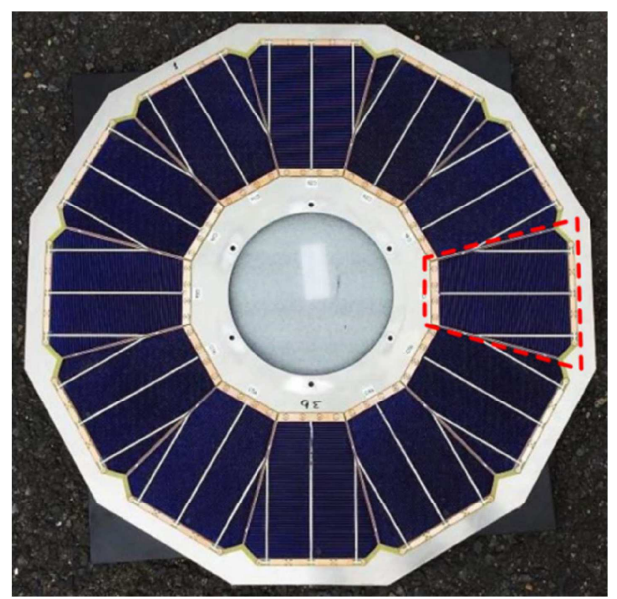

Figure 11. PVT assembly. The dashed line delimitates one cut PVT. The diameter of the assembly is $33 \mathrm{~cm}$.
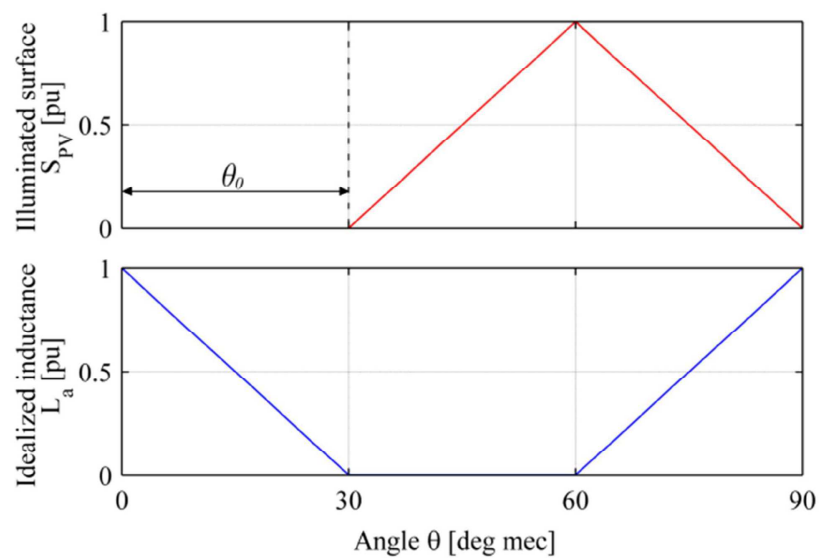

Figure 12. Top: Normalized illuminated PVT surface. Bottom: Idealized phase inductance $\mathrm{L}_{\mathrm{a}} \cdot \theta=0$ deg corresponds to the SRM aligned position. The shutter synchronization is defined by $\theta_{0}$. 

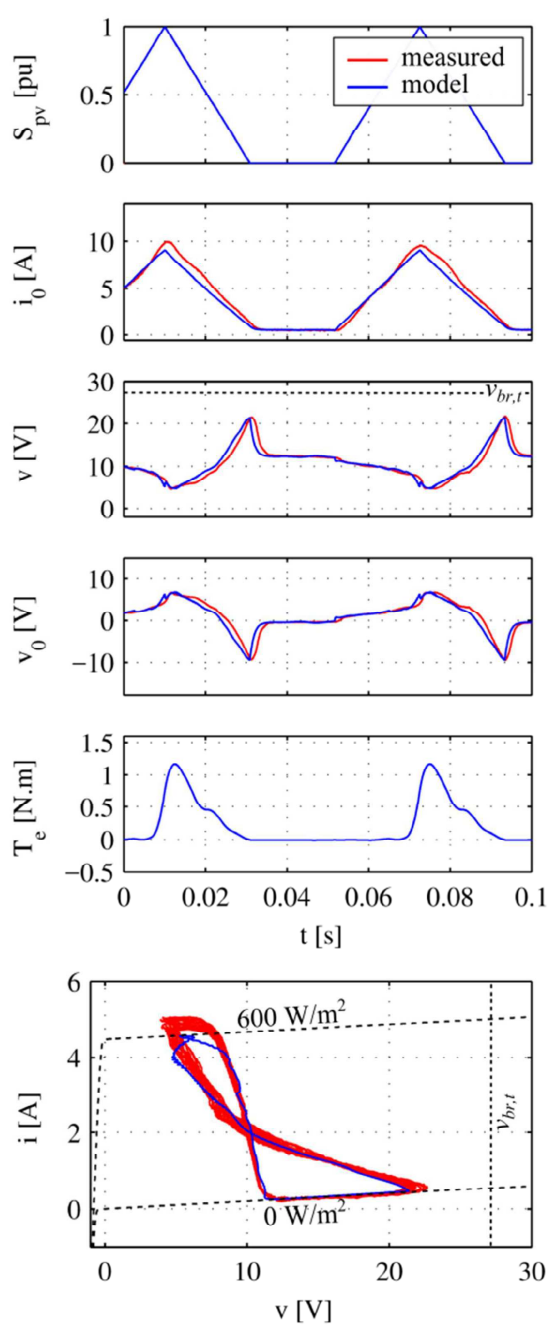

(A) $T_{M}=0.86 \mathrm{~N} \cdot \mathrm{m}(240 \mathrm{r} / \mathrm{min})$
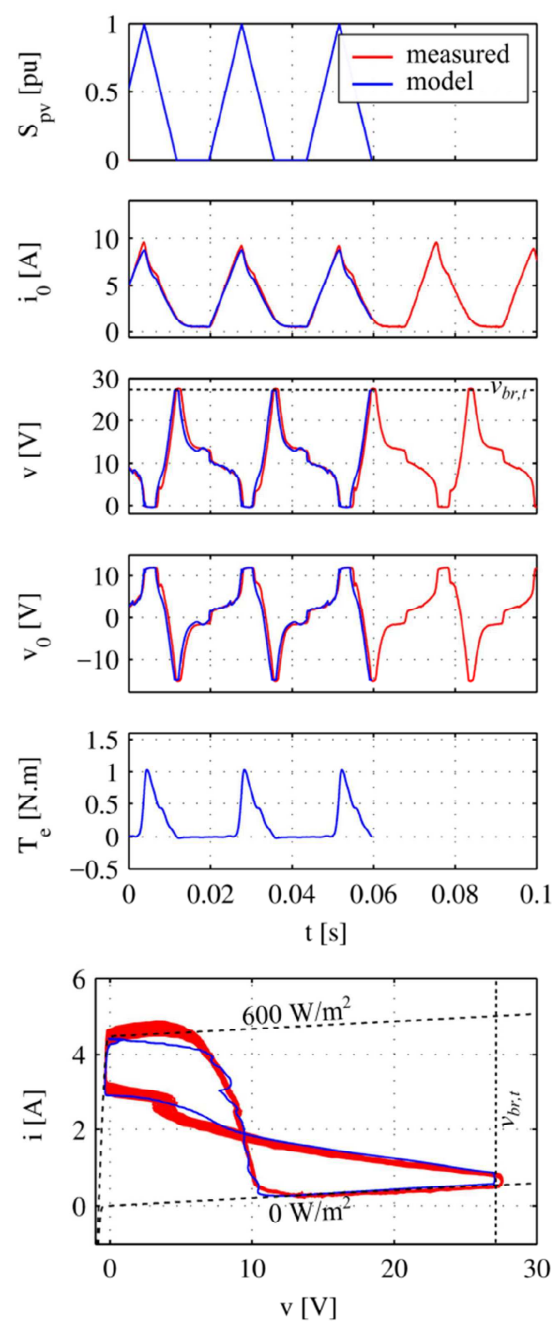

(B) $T_{M}=0.65 \mathrm{~N} \cdot \mathrm{m}(628 \mathrm{r} / \mathrm{min})$
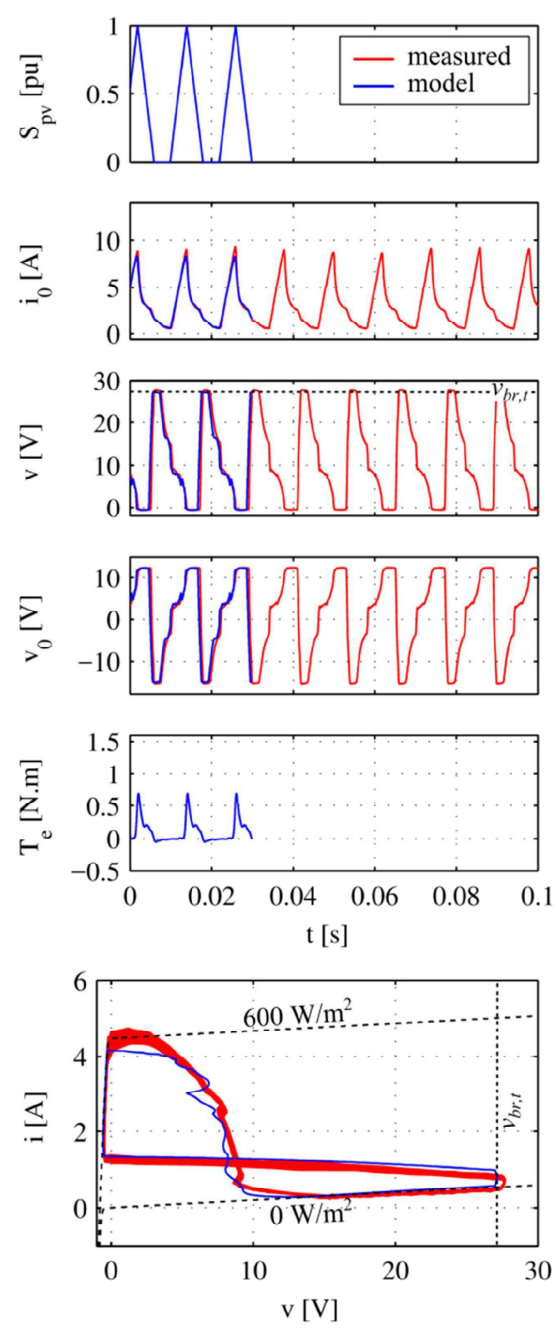

(C) $T_{M}=0 \mathrm{~N} \cdot \mathrm{m}(1250 \mathrm{r} / \mathrm{min})$

Figure 13. Experimental and simulation results for various applied braking torque $T_{M}$, for $\theta_{0}=30$ deg under a mean illumination $I_{\text {sol }} \approx 600 \mathrm{~W} / \mathrm{m}^{2} . v, v_{0}$, and $i_{0}$ are defined in Fig. 9. $i$ is the PVT current $\left(i=i_{0} / 2\right) . S_{P V}$ is the simulated PVT illuminated surface. $T_{e}$ is the simulated instantaneous electromagnetic torque per half-phase. $v_{b r, t}$ is the transil diode breakdown voltage.

\section{E. Discussion}

Previous measurements and simulations reveal some characteristics of the system, which can be useful in the future for optimizing the system. Consider Fig. 13:

- At point $(A$, corresponding to low speed and high torque operation, the half-phase current has the same triangular shape as the PVT illuminated surface. This indicates that the current is well controlled by the PVT.

- At point (B), near the maximum power point, the halfphase current is quasi-triangular. It is then still controlled by the PVT but with voltage limitations. During the magnetization, the PVT operates shortly in generator mode (quadrant II, see Fig. 2). During the demagnetization, as there is no current freewheeling, the current does not go back to the power supply but continues flowing through the PVT. As a result the PVT voltage increases till it reaches the transil diode breakdown voltage $\left(v_{b r, t}=27 \mathrm{~V}\right)$. Then the demagnetization current goes through the transil diode. The transil diode enables us to apply the maximal negative voltage to the half-phase. Thus the demagnetization is dissipative.

- At point $\odot$, corresponding to high speed and low torque, the half-phase voltage tends to the voltage that would be obtained with a full wave voltage supply. During most of the magnetization, the half-phase positive voltage is maximal thanks to the PVT operating in quadrant II. And during most of the demagnetization, the half-phase negative voltage is maximal while the PVT voltage is limited to the transil diode breakdown voltage $v_{b r, t}$. 


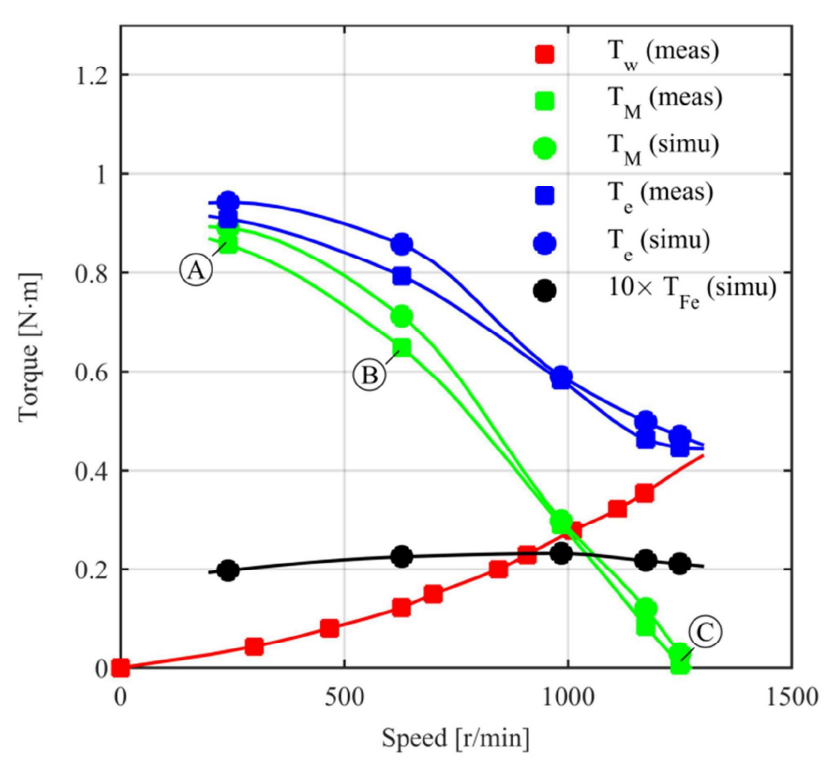

Figure 14. Experimental and simulated torque-speed curves for $\theta_{0}=30 \mathrm{deg}$ under a mean illumination $I_{\text {sol }} \approx 600 \mathrm{~W} / \mathrm{m}^{2} . T_{w}$ is the friction torque (bearings, windage and shutter), $T_{M}$ is the output mechanical torque, $T_{e}$ is the electromagnetic torque. $T_{F e}$ is the torque associated with iron loss ( $T_{e}-T_{F e}-T_{w}-T_{M}=0$ in steady-state operation).

Finally, the model allows us to predict the performance of our PVT inverter-fed SRM for other operating conditions. For example, under a mean illumination of $1000 \mathrm{~W} / \mathrm{m}^{2}$ with all the 6 half-phases connected to a $12 \mathrm{~V} \mathrm{DC}$ power source, the maximum output mechanical power is estimated to $\sim 130 \mathrm{~W}$ at $650 \mathrm{r} / \mathrm{min}$. This is sufficient for applications such as standalone water pumping, and could be even increased by optimizing the drive.

\section{CONCLUSION}

We introduced a new solar electric motor architecture that uses photovoltaic cells as light-controlled transistors with an optical shutter. This system can be considered as an improvement of the "photovoltaic switched reluctance motor" described in $[3,4]$. The use of solar cells as light-controlled power transistors is original, and could be extended to other applications.

As a proof of concept, we assembled and tested successfully the first PVT inverter-fed SRM. Because of its unique operating principle and the high nonlinearity of its components (PVT and SRM), we needed a good model of this system in order to evaluate its range of applications, then to optimize the output power with minimal global cost. Here we modeled the system in a bottom-up approach, starting by the PVTs. Our model has been validated on the full speed range by comparison with measurements made on our prototype supplied by a DC voltage source.

Later the model will be extended to simulate a PVT inverter-fed SRM supplied by an external solar PV source. This will add complexity because the external solar PV source operating point will vary continuously. In parallel, more work

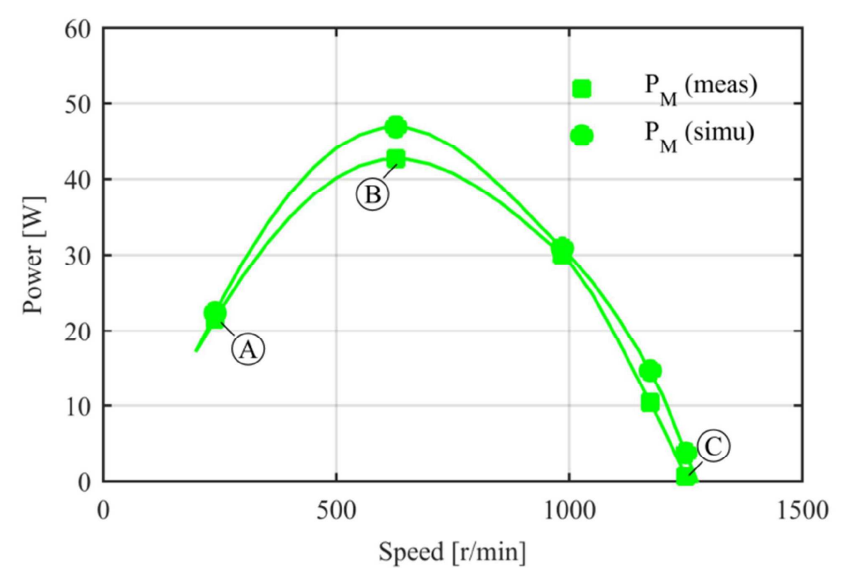

Figure 15. Experimental and simulated output mechanical power-speed curves for $\theta_{0}=30 \mathrm{deg}$ under a mean illumination $I_{\text {sol }} \approx 600 \mathrm{~W} / \mathrm{m}^{2}$.

is needed to optimize the drive (PVT and electromagnetic structure), enhance the performances of the PVTs and test the system's reliability.

Such architecture is expected to be well suited for fully autonomous applications in isolated areas where reliability is a major concern, like water pumping with storage in a water tank. The efficiency of the PVT inverter-fed SRM is low, but (a) the energy input is free, (b) the price of solar cells has been sharply decreasing, (c) the price of the drive may be quite acceptable, and (d) the balance of consumption of nonrenewable primary energy over the overall life cycle should be very good, but it remains to be demonstrated. Work is underway to optimize the system taking reliability into account, and to estimate its cost on overall life cycle, which is an appropriate metric to evaluate if the low efficiency can be compensated by a higher reliability.

\section{REFERENCES}

[1] J. Appelbaum, "Starting and steady-state characteristics of DC motors powered by solar cell generators," IEEE Transactions on Energy Conversion, vol. EC-1, no. 1, pp. 17-25, 1986.

[2] S.R. Bhat, A. Pittet, B.S. Sonde, "Performance optimization of induction motor-pump system using photovoltaic energy source," IEEE Trans. on Industry Applications, vol. IA-23, no. 6, pp. 995-1000, 1987.

[3] L. Quéval, A. Coty, L. Vido, B. Multon, "Photovoltaic motors review, comparison and switched reluctance motor prototype," 10th Int. Conf. on Ecological Vehicles and Renewable Energies (EVER2015), Monaco, April 2015.

[4] L. Quéval, A. Coty, L. Vido, R. Gottkehaskamp, B. Multon, "Photovoltaic switched reluctance motor modeling and simulation," 15th IEEE Int. Conf. on Environment and Electrical Engineering (EEEIC2015), Rome, Italy, June 2015.

[5] L. Quéval, A. Coty, L. Vido, R. Gottkehaskamp, B. Multon, "A switched reluctance motor drive using photovoltaic transistors: principle, prototype, experimental and numerical results," 4th Int. Conf. on Renewable Energy Research and Applications (ICRERA 2015), Palermo, Italy, November 2015.

[6] K. Meah, S. Fletcher, S. Ula, "Solar photovoltaic water pumping for remote locations," Renewable and Sustainable Energy Reviews, vol. 12, pp. 472-487, 2008.

[7] S.S. Chandel, M. Nagaraju Naik, R. Chandel, "Review of solar photovoltaic water pumping system technology for irrigation and 
community drinking water supplies," Renewable and Sustainable Energy Reviews, vol. 49, pp. 1084-1099, 2015.

[8] V.C. Sontake, V.R. Kalamkar, "Solar photovoltaic water pumping system - A comprehensive review," Renewable and Sustainable Energy Reviews, vol. 59, pp. 1038-1067, 2016.

[9] L. Devol, "Motor," U.S. Patent 2968 756, Jan. 17, 1961.

[10] I.W. Cox, "Motor control system," U.S. Patent 3023 348, Feb. 27, 1962.

[11] J.H. Wessels, "Self-starting direct-current motors having no commutator," U.S. Patent 3299 335, Jan. 17, 1967.

[12] R.K. Hill, "Brushless direct current motor," U.S. Patent 3364 407, Jan. $16,1968$.

[13] W.W. French, "Optically commutated self-rotating drive mechanism," U.S. Patent 2007/0075599A1, Apr. 5, 2007.

[14] E.H. Levi, "Light actuated rotational transmitter," U.S. Patent 3239 734, Mar. 8, 1966.

[15] Y. Nakamats, "Energy conversion apparatus for converting radiant energy to rotary force," U.S. Patent 5731 676, Mar. 24, 1998.

[16] A. Coty, "Autoswitched photovoltaic motor with augmented power," EU. Patent WO2012069447, May. 31, 2012.

[17] C. Ungureanu, "Operating analysis of solar electric motors," Buletinul AGIR, nr. 4, pp. 222-228, 2012.

[18] MPO Energy, MPO Solo monocrystalline cells, data sheet 3BM56.01.

[19] J.A. Gow, C.D. Manning, "Development of a photovoltaic array model for use in power-electronics simulation studies," IEE Proc.-Electr. Power Appl., vol. 146, no. 2, 1999.

[20] MATLAB Release 2011b, The MathWorks, Inc.

[21] T.J.E. Miller, Switched Reluctance Motors And Their Control, Magna Physics Pub., 1993.

[22] H. Le-Huy, P. Brunelle, "A versatile nonlinear switched reluctance motor model in Simulink using realistic and analytical magnetization characteristics," IEEE 31st Annual Conf. of Industrial Electronics Society (IECON 2005), pp. 1556-1561, 2005.

[23] L. Quéval, H. Ohsaki, "Nonlinear abc-model for electrical machines using N-D lookup tables," IEEE Trans. on Energy Conversion, vol. 30, no. 1 , pp. 316-322, 2015 